\title{
MICROFOUNDATIONS OF SOCIAL THEORY: A RESPONSE TO JEPPERSON AND MEYER*
}

\author{
Teppo Felin \\ Marriott School \\ Brigham Young University \\ Provo, UT 84602; USA \\ teppo.felin@byu.edu \\ Nicolai Foss \\ Department of Strategic Management and Globalization \\ Copenhagen Business School \\ Kilevej 14, 2nd floor \\ 2000 Frederiksberg; Denmark \\ njf.smg@cbs.dk \\ and \\ Department of Strategy and Management \\ Norwegian School of Economics and Business Administration \\ Breiviksveien 40; N-5045; Bergen; Norway \\ Peter Abell \\ Managerial Economics and Strategy Group \\ Department of Management \\ London School of Economics \\ p.abell@1se.ac.uk
}

\begin{abstract}
In this short essay we respond to Jepperson and Meyer's (2011) critique of "action theories" and methodological individualism in sociology. We highlight fundamental problems with their argument, notably their misconception of methodological individualism(s) and the belief that this explanatory principle ignores - and is somehow invalidated by - the complex, "emergent" and multi-level nature of social phenomena. We focus on the need to specify and understand 1) component actors and social complexity, 2) theory of action, aggregation, and emergence, 3) process and the context of action. We concurrently critique Jepperson and Meyer's own (implicit but highly problematic and under-specified) theory of action.
\end{abstract}

Key words: micro-macro, aggregation and emergence, social theory, multi-level theorizing

\footnotetext{
* We would like to thank Ian Jarvie (York University), Brayden King (Northwestern University), Omar Lizardo (University of Notre Dame), and Petri Ylikoski (University of Helsinki) for excellent comments on earlier versions of this essay. The opinions expressed in this response are ours and do not implicate them in any way.
} 


\section{INTRODUCTION}

In this short essay we respond to Jepperson and Meyer's (2011) (henceforth J\&M) recent, provocative article on methodological individualism in sociology. In their article J\&M make some rather strong claims against the allegedly "micro-chauvinist," "doctrinal and exclusivist" microfoundations program of research in social theory and particularly its foundations in methodological individualism (henceforth MI). They argue that MI disregards multi-level causation and conflates microfoundations with explanation. J\&M further argue that $\mathrm{MI}$ is founded on "liberal and American cultural models of society [that] notoriously dramatize and valorize purposive individual action." J\&M call for a focus on higher-level, "emergent" properties and a more "scientific," "contextualized" and multi-level approach to social theory that focuses on "biological, ecological, structural, and cultural causation and hence the displacement of action theories" (italics added).

J\&M's attempt to discredit and displace purposive action and choice-oriented approaches is quite surprising to us and counter to what we see as some of the more exciting theorizing in sociology, both past and present. In response, we are tempted to re-iterate the reasons - none of which are dealt with by $\mathrm{J} \& \mathrm{M}$ - that have already been provided for an emphasis upon microfoundations and MI. For example, James Coleman in his Foundations of Social Theory provides five "points favoring the internal analysis of system behavior" (1990: 3-5; also see Coleman, 1986) and also persuasively discusses "why [we should] use a theory of purposive action" (1990: 16-20; also see Abell, 2003; Abell et al., 2008). However, instead of summarizing existing work, ${ }^{1}$ we address some of the specific misconceptions that J\&M have regarding the nature, purposes and multi-level implications of MI on sociological explanation. ${ }^{2}$ We also concurrently critique J\&M's own theory of actor-hood and action, which remains implicit but is highly problematic.

\section{COMPONENT ACTORS AND SOCIAL COMPLEXITY}

$\mathrm{J} \& \mathrm{M}$ argue that structures have sui generis, "emergent" properties that have independent causal influence and thus a focus on the "micro" should not be privileged in any way. They cite work on networks, structure, institutions and focus on "social-organizational" and "institutional processes." In general, their point is that multi-level "complexity" and the "emergent" properties and inter-relationships between levels and structures are central. For example, J\&M discuss how "institutions are chronically reproducing complexes of routines, rules, roles, and meanings." J\&M further argue that "in many cases a social process, precisely because it represents 'organized complexity,' may have individual-level "realizations" that are too heterogeneous or complex to theorize."

We agree that social life is complex. But contrary to J\&M we consider social complexity, emergence, and appeals to multi-level processes as mere re-statements of the problem of social theory rather than a basis for explanation. Social complexity is not a refutation against MI but rather an argument for it. Of course social life is complex and institutions matter, as do routines, rules, roles, meanings and so forth. But the immediate questions are: what exactly is social complexity? Can we dimensionalize and explain it via the interactions of component parts and

\footnotetext{
${ }^{1}$ Given space limitations, we will not directly address J\&M's discussion of the micro-macro links in Weber's "Protestant Ethic"-thesis, as this is already persuasively done by Coleman and others (see Coleman 1986: 1320-1325; also see Coleman 1990: 6-9).

${ }^{2}$ We recognize that there are various weaker and stronger forms of methodological individualism in social theory, as thoroughly explicated by Udehn (2001). J\&M's critique of "individualisms," in the plural, suggests that their critique is seemingly applicable to all these forms. Furthermore, the question of the role of "action" is also at stake in this discussion and debate, a matter that is intimately tied to most forms of methodological individualism (cf. Coleman, 1986).
} 
processes? What precisely are these rules and institutions, how do they enable or delimit individual and collective action, where do they come from, what is the role of actors in creating and sustaining them?

Simply citing and appealing to social "complexity" or "emergence" or "sets of social processes" (more on this later) - and definitionally layering social concepts upon each other: routines, roles, institutions, etc - only restates the problem faced by the social theorist rather than meaningfully solving it. Citing "emergence" is only an admission of ignorance (see Nagel 1961 on the "doctrine of emergence"), and it doesn't explain or tell us how and why something emerged.

The tendency to pack concepts tightly - piling aspects of social complexity one upon another-, without offering clear definitions has indeed been a problem in "grand" social theorizing, including neo-institutional theory. As noted by Heather Haveman, herself a contributor to institutional theory: "if institution and institutionalization mean everything and explain everything - change and stability, individual routines, organizational structures, and societal cultures; cognitive, regulatory, and normative processes - then they mean nothing and explain nothing" (2000: 478). Indeed, the frustration with grand, structural theorizing-withoutchoice has manifested itself in other areas of social theory, not just institutional theory (also see Hirsch, 1997). For example, James Jasper highlights how extant social movements research is "dominated by structural metaphors" (2004: 1). He argues that "structural models of the last thirty years may have reached the limit of their usefulness" in the social movements literature, and calls for more work that pays "attention to the microfoundations of political action," namely, the "strategic choices" and "tactics" that movement actors, organizers and participants necessarily make and use when faced with various dilemmas.

We maintain that a fundamental problem of much social theorizing derives from this high-level macro focus and the excision of individual-level and collective action and agency. As noted by Selznick, "no social process can be understood save as it is located in the behavior of individuals" (1996: 274). This might be the version of ontological individualism that J\&M are comfortable with. But this ontological truth, beyond the fact that rules or roles are enacted by people, must also - as we will discuss below - carry operational implications for the nature of social theorizing in terms of the decisions that individual and social actors make.

It is indeed worthwhile to note here that J\&M's critique of MI, building on their previous work (cf. Jepperson and Meyer, 2000), embodies an implicit theory and assumptions about action, but for them "actorhood" is a cultural and social construction. But to see actors as simple, compliant enactors of institutions does not, in any way, help us explain 1) the striking heterogeneity of organizations, forms and collective action, 2) the emergence and boundaries of these social activities, and 3) change and "purposively constructed organization" (Coleman, 1991). The social world that we observe around us is not homogeneous and static, it has shape and is dynamic due to heterogeneity at the individual and collective levels. As we will discuss, individuals and actors make choices about what actions to take, where to work, with whom they interact or align themselves and so forth and these choices shape the social fabric that we observe. Organizations similarly take strategic actions that influence their environments (see King et al., 2010 for a discussion of a form of "institutional individualism" in organization theory).

MI then is a natural starting point for understanding collective phenomena and structures because it attempts to unpack the constituent and component parts, their underlying interests, beliefs, preferences, strategies and interactions and to theorize how phenomena, structures, institutions and so forth are generated, maintained and evolve. Whilst extant social theorizing doesn't always use the language of MI—nonetheless similar "disaggregational" intuition can quite readily be found in a wide variety of social theories. For example, John Levi Martin begins his book — with strikingly similar tones to Coleman's meta-theory (1990: 1-23) — by highlighting the need to "identify components of structure" and he argues "that structure can be produced via the aggregation of these components" (2009: 1). Others have advocated a need to move social 
analysis from the study of collective "factors" (such as institutions) to the study of component "actors"- to study how institutions and collective structures emerge and evolve from individuallevel intentions, expectations and interactions (Macy and Willer 2002). Many recent models rely upon a type of "generative process theory" or "generative structuralism" where individuals and their choices and interactions are carefully specified in an effort to understand and "grow" emergent social outcomes, norms and institutions (Cederman 2005; Chwe, 2001; Fararo, 1989; Schelling 1971). This sentiment is shared by some social anthropologists who argue that institutions, rules and norms need to be explained "as an outcome of the choices and alignments made by their participants" (Barth, 2007: 3). We agree.

\section{THEORY OF ACTION, AGGREGATION AND EMERGENCE}

J\&M deeply misunderstand MI by arguing that it focuses on a "mass of similar [or "modal"] individuals" and what they call "plebiscitary" or "market-like" aggregation. The truth is precisely the opposite. Central to MI is a need to understand how diverse and heterogeneous interests, beliefs, expectations and so forth are (somehow) aggregated in various ways, leading (or not) to collective equilibria. If individuals are fundamentally alike, homogeneous, and interact in a simple manner, then we may indeed be able to dispense with them (only allowing them to "enact" rather than "act") and their interactions and focus directly — as J\&M advocate - upon macro-relations. But individuals are heterogeneous in their interests and preferences and varied patterns and processes of aggregation and social aggregation provide the central problem for social theory.

As justification for jumping directly to the macro-level, J\&M again appeal to "organized complexity" and even argue this complexity may have individual-level "realizations" that are too heterogeneous or complex to theorize." But this "complex" theoretical work, again, is precisely the stuff of social theory. MI helps create clarity and more persuasive explanations by disaggregating concepts and constituent parts, their interaction, and associated processes of aggregation and evolution. MI indeed is naturally concerned with the many different kinds of mechanisms through which the interaction of individuals, in a context (organization), via various organizational forms (e.g., Simmel, 1974) give rise to emergent collective outcomes (e.g., Schelling, 1978). Moreover, MI places a premium on carefully detailing the interactional and influence processes that might lead to an "emergent" social outcome (cf. Wimsatt, 1996).

It is important to note that MI by no means requires that actions are of some omniscient or heroic variety, rather collective outcomes can truly be surprising and emergent: the macro might be the "result of human action but not of human design." In other words, individuals have interests or beliefs that guide their activities, but the macro, social outcomes may be emergent from individual action and interaction (Ullmann-Margalit, 1977). For theorists who have pointed out these "emergent" social outcomes (including social theorists associated with the Scottish Enlightenment ${ }^{3}$ ), complexity at both the micro and macro-levels and MI are entirely compatible (Hayek, 1964). The onus then is on the social theorist to explain how social complexity or equilibria arise as the result of choices, interactions and so forth, and possibly how the resulting macro patterns (e.g., market outcomes, institutions) are sustained.

While we have thus far emphasized heterogeneity (both at the micro and macro levels),

\footnotetext{
${ }^{3}$ Note that there is really nothing new or revolutionary in our call for sociological theory that is methodologically individualist. Although J\&M portray the call for micro-foundations in individualist vein as a recent, "American" undertaking, it has been at the heart of social science since at least the Scottish Enlightenment. Furthermore, social theorists from Friedrich Hayek, Karl Popper, Gabriel Tarde, Georg Simmel and Max Weber, to contemporary economists and rational choice sociologists, have seen individualist explanation as a powerful starting point for social theorizing.
} 
$\mathrm{J} \& \mathrm{M}$ of course focus directly on the various homogeneous equilibria that we can readily observe around us. But there is much evidence that this homogeneity also is the result of underlying micro-dynamics and heterogeneity.

In fact, one illustration of the power of MI is the fact that much of the social fabric that we observe is created through processes of self-selection and matching. Heterogeneous actors make choices about which groups to belong to, who to interact with, whether to reproduce certain institutions and so forth. If we miss the a priori beliefs, expectations, values of individuals, then we don't recognize that "common values precede rather than follow from social interaction" (Katz and Lazarsfeld, 1955: 59-60). Thus it merely looks like structural and cultural homogeneity reigns - as J\&M would have it — but looks can be deceiving in terms of the underlying mechanisms that give rise to this homogeneity. To dismiss the decisions of individual-level actors, even when faced with macro uniformity, is to miss a large swath of social activity. As highlighted by Simmel — who began his analysis with "component individuals""society exists where a number of individuals enter into interaction" (1972: 23). Social theorists, such as Tocqueville, also note that "as soon as [individuals] have conceived a sentiment or an idea that they want to produce in the world, they seek each other out; and when they have found each other; they unite" (2000 [1840]: 492). Or, if individuals are unsatisfied with their social institutions and context, they leave or exert "voice" (Hirschman, 1970). These types of bottomup social processes are central for understanding the social structures that we observe around us. The literature on homophily shows precisely how some structures emerge as individuals selfselect to interact with similar others, including friendship ties (Kandel 1978), common aspirations (Cohen 1983), marriage (Kalmijn 1998) and so forth (McPherson et al. 2001).

Macro theorizing tends to lead to empirical work that shows correlations between, say, an aspect of network structure and creative outcomes (Uzzi and Spiro 2005)—falsely ascribing causation to the network or structure itself, assuming the nodes are homogeneous and randomly distributed, rather than recognizing the heterogeneity and important self-selection and individuallevel matching processes that precede the formation of networks. While J\&M argue that "sociological explanation should be an empirical rather than doctrinal matter," explanations with micro-foundations are more reliable and true to the nature of social reality, as our discussion of self-selection illustrates. Thus extant structures and institutions can't be taken as the primitives of social theorizing as they are the result of the choices and self-selection processes that precede them. After all, if individuals are dis-satisfied with extant organizations or institutions, they (very often) have choices about what to do-such as "exit," "voice" or "loyalty" (Hirschman 1970).

\section{PROCESS AND THE CONTEXT OF ACTION}

In their article J\&M appeal to various types of "processes" frequently - they use the word "process" 57 times. But the problem is that actor-less process approaches cannot explain the underlying heterogeneity and conflicts of actors and the resultant social choices and equilibria that emerge, specifically as they take the existence of various equilibria and institutions for granted. In other words, J\&M's approach is essentially antithetical to process as it focuses on the "nouns" rather than "verbs" of organizing (e.g., "institutions" rather than "institutionalization"). In these models "compliance" appears to be the operative mechanisms, and social control (somehow) "just happens" (Hirsch, 1997: 1702). This point has been lamented by institutional scholars themselves. For example, Selznick (1996) persuasively argues that actor choices are central for understanding the process of institutionalization but the explication of these processes has been missing from neo-institutional arguments. DiMaggio also emphasizes that "there is much about the processes by which institutions emerge, are reproduced and erode that cannot be explained without reference to interest and group conflict" (1988: 4). The scope of J\&M-like social theories-where strong compliance is assumed and social equilibria are taken for granted - then is extremely limited. More recently a similar critique has also been made by scholars interested in "institutional work." They argue for the need to understand the choices, 
alignments, and strategies of the actors that create, sustain and change emergent and evolving institutions (Lawrence, Suddaby, and Leca, 2009).

Our emphasis on choice and action certainly does not mean that activities happen in a vacuum, without constraints or outside of social context. Various multi-level considerations in fact are in perfect harmony with MI, a point explicitly brought out by the simple Coleman diagram that J\&M so strongly criticize (and which led Bunge [1997: 454] to essentially accuse Coleman of being a "closet systemist"). In other words, MI is in perfect harmony with the fact that choices are made within extant structures that enable and constrain action (cf. Ingram and Clay, 1998). These structures can represent various things: extant networks and social relations, hierarchy and organizational forms, past decisions and routines, rules and norms and so forth. All of this can be modeled.

But the key issue is to ensure that the resulting social theory is not overly structural and deterministic where the social theorist effectively "loses their problem" by simply postulating, naming or observing these structures rather than explaining their origin from lower-level antecedents and subsequent evolution and change (cf. Coleman, 1986: 1312).

Microfoundations-based approaches are explicitly cognizant of the need to specify the boundaries of human decision-making, recognizing that rationality and choices are both bounded and enabled by various cognitive, spatial, organizational and social factors. Thus the rationality of actors scarcely needs to be of some omniscient or homogeneous variety. Again, citing Selznick: "[individual] behavior does not necessarily conform to rational-actor models, but it very often does include attention to short-term opportunities, constraints and incentives. We need a better understanding of multiple and bounded rationalities - not merely to show that they existincluding much that is encompassed in economizing models. A focus on responsive and problem-solving behavior is a helpful bridge between the non-rational and the rational. Of course non rational should not be conflated with irrational" (1996: 275-276).

Thus most models of choice and interaction specify some level of existing structure, network or incentives within which choices are made. In other words, we want to understand the "aggregate of people exercising choice while influenced by certain constraints and incentives" (Barth 1981: 34). J\&M argue that "contextualization presents a problem for those who would privilege individual-level explanation.” It doesn't. Quite the opposite. Social structures not only can be generated via individualist explanations, but their enabling and constraining nature can also readily be modeled, as clearly illustrated by the Coleman diagram that J\&M criticize. As an example, new institutional and political economists are busy modeling the impact of formal and informal institutions on the choice sets faced by individuals (e.g., North, 1990; Ostrom, 1990; Williamson, 1996), how the selection of these institutions is (partly) a matter of their consequences for individuals, and how they are changed as scarcities and technologies evolve in response to learning. Social theorists may balk at the fact that economists mainly study the incentive properties of such institutions, but surely incentives are also part of social context within which actions take place.

\section{CONCLUSION}

J\&M seek the "displacement of action theories" in social theory. We disagree, in numerous ways. First, their arguments for displacing action theories focus on social, multi-level complexity, but this only - as we have discussed - reinforces the need to disaggregate and understand the constituent actors that make up social systems. Second, we take issue with what we see as their numerous misrepresentations of MI. For example, it simply is not true that MI presupposes individual level homogeneity, quite to the contrary. The purpose of MI is specifically to understand how heterogeneous interests, preferences and conflict is resolved (or not), leading to various social outcomes and equilibria that in turn shape subsequent action. Third, we do not find that J\&M have presented a logical argument for their central assertion, namely that the "micro-foundations of social-organizational and institutional causal pathways are not equivalent 
to causal arguments at the level of individuals conceived as actors." This remains a postulate that is wedded to a false opposition between individuals "enacting highly institutionalized roles", on the one hand, and "functioning as individual actors" on the other hand. Fourth, J\&M's own implicit theory of action simply is incongruent with specifying the underlying social processes that they talk about. Furthermore, J\&M's actor-less, compliance-based model is applicable to a very limited set of social settings, and thus we have highlighted that "action" should be at the heart of social theory rather than actively "displaced."

\section{REFERENCES}

Abell, Peter. 2003. "The role of rational choice and narrative action theories in sociological theory: the legacy of Coleman's Foundations." Revue Francaise de Sociologie 44: 255273.

Abell, Peter, Teppo Felin and Nicolai Foss. 2008. "Building microfoundations for the routines, capabilities, and performance links." Managerial and Decision Economics 29: 489-502.

Barth, Roland. 1981. Process and Form in Social Life: Selected Essays of Fredrik Barth. London: Routledge.

Barth, Roland. 2007. "Overview: sixty years in anthropology." Annual Review of Anthropology 36: 1-16.

Bunge, Mario. 1997. "Mechanism and explanation." Philosophy of the Social Sciences 27: 410465.

Cederman, Lars-Erik. 2005. "Computational models of social forms: Advancing generative process theory." American Journal of Sociology 110: 864-893.

Chwe, Michael. 2001. Rational Ritual: Culture, Coordination and Common Knowledge. Princeton: Princeton University Press.

Cohen, Jere. 1983. "Peer influence on college aspirations with initial aspirations controlled." American Sociological Review 48: 728-734.

Coleman, James. 1986. "Social theory, social research and a theory of action." American Journal of Sociology 91: 1309-1335.

Coleman, James. 1990. Foundations of Social Theory. Cambridge, MA, and London: The Belknap Press of Harvard University Press.

Coleman, James. 1991. Constructed organization: First principles. Journal of Law, Economics, and Organization 7: 7-23.

Fararo, Thomas. 1989. The Meaning of General Theoretical Sociology: Tradition and Formalisation. Cambridge University Press.

Haveman, Heather. 2000. "The future of organizational sociology: forging ties among paradigms." Contemporary Sociology 29: 476-486.

Hayek, Friedrich 1964. "The theory of complex phenomena." Studies in Philosophy, Politics and 
Economics. London: Routledge and Kegan Paul.

Hedström, Peter. 2005. Dissecting the Social: On the Principles of Analytical Sociology. Cambridge University Press.

Hirsch, P. 1997. Sociology without social structure: neoinstitutional theory meets brave new world. American Journal of Sociology 102: 1702-1723.

Hirschman, Albert. 1970. Exit, Voice and Loyalty. Princeton, NJ: Princeton University Press.

Ingram, Paul and Karen Clay. 2000. "The choice-within-constraints new institutionalism and implications for sociology." American Sociological Review 26: 525-546.

Jasper, James. 2004. "A strategic approach to collective action: Looking for agency in social movement choices." Mobilization 9: 1-16.

Jepperson, Ronald and John Meyer. 2001. “The 'actors' of modern society: The cultural construction of social agency." Sociological Theory 18: 100-120.

Jepperson, Ronald and John Meyer. 2011. "Multiple levels of analysis and the limitations of methodological individualisms." Sociological Theory 29: 54-73.

Kalmijn, Matthijs. 1998. "Intermarriage and homogamy: causes, patterns and trends." Annual Review of Sociology 84: 427-436.

Kandel, Denise. 1978. "Homophily, selection and socialization in adolescent friendships." American Journal of Sociology 84: 427-436.

Katz, Elihu and Paul Lazarsfeld. 1955. Personal Influence: The Part Played by People in the Flow of Communications. New York: The Free Press.

King, Brayden, Teppo Felin and David Whetten. 2010. "Finding the organization in organization theory: A meta-theory of the organization as social actor." Organization Science 21: 290-305.

Lawrence, Thomas, Roy Suddaby and Bernard Leca. 2009. Institutional Work: Actors and Agency in Institutional Studies of Organizations. Cambridge University Press.

Macy, Michael and Robb Willer. 2002. "From factors to actors: Computational sociology and agent-based modeling." Annual Review of Sociology 28:143-166.

Martin, John Levi. 2009. Social Structures. Princeton University Press.

McPherson, Miller, Lynn Smith-Lovin, and James Cook. 2001. "Birds of a feather: Homophily in social networks.” Annual Review of Sociology 27: 415-444.

Nagel, E. 1961. The Structure of Science: Problems in the Logic of Scientific Explanation. Hackett Publishing.

North, Douglass C. 1990. Institutions, Institutional Change, and Economic Performance. Cambridge: Cambridge University Press. 
Ostrom, Elinor. 1990. Governing the Commons: The Evolution of Institutions for Collective Action. New York: Cambridge University Press.

Schelling, Thomas. 1971. "Dynamic models of segregation.” Journal of Mathematical Sociology $1: 143-186$.

Selznick, Philip. 1996. "Institutionalism old and new. "Administrative Science Quarterly 41: 270-277.

Simmel, Georg. 1974. Individuality and Social Forms. University of Chicago Press.

Tocqueville, Alexis. 2000 [1840]. Democracy in America. Chicago: The University of Chicago Press.

Uzzi, Brian and Jarrett Spiro. 2005. "Collaboration and creativity: the small world problem." American Journal of Sociology 111: 447-504.

Udehn, Lars. 2001. Methodological Individualism: Background, History and Meaning. Routledge.

Ullmann-Margalit, E. 1977. The Emergence of Norms. Oxford University Press.

Williamson, Oliver E. 1996. The Mechanisms of Governance. Oxford: Oxford University Press.

Wimsatt, William C. 1997. "Aggregativity: Reductive heuristics for finding emergence.” Philosophy of Science 64: 372-384. 